\title{
A CASE OF INTRACRANIAL DERMOID CYST ASSOCIATED WITH THE KLIPPEL-FEIL DEFORMITY AND RECURRENT MENINGITIS
}

BY

\author{
A. PETER ROBERTS \\ From the Children's Hospital, Birmingham
}

(RECEIVED FOR PUBLICATION OCTOBER 1, 1957)

Intracranial dermoid cysts are rare: of 2,023 verified intracranial tumours recorded by Cushing (1932) there were 15 examples, including epidermoid cysts. In many cases there is an associated congenital dermal sinus. The following is presented as a typical case.

\section{Case Report}

D.H. is the second child of healthy parents, the elder child being normal. He was first referred to the Children's Hospital in July, 1954, at the age of 4 weeks because of diarrhoea and vomiting. This was thought to be dietetic in origin, and the only abnormal finding was the presence of the Klippel-Feil deformity, which was confirmed by radiological examination (Fig. 1).

Ten months later he was admitted with acute bronchitis, and examination at that time revealed a small mobile lump in the occipital region. This was considered to be a fibroma.

He then remained well for 15 months until August, 1956 , when he was readmitted with a two-day history of refusal to eat, vomiting and drowsiness. He was extremely irritable and crying more than usual, especially if disturbed.

On examination owing to his spinal deformity it was not possible to confirm any neck stiffness. There was no papilloedema.

Lumbar puncture yielded a cloudy fluid containing 3,250 white cells per c.mm., most of which were polymorphonuclear. The protein content was $700 \mathrm{mg}$. \%, the sugar $6 \mathrm{mg}$. \% and the fluid was sterile on culture.

A diagnosis of probable meningococcal meningitis was made: he was treated with penicillin and sulphadimidine and his progress was satisfactory.

Soon after returning home vomiting recurred. He was crying continuously, banging his head and he was noticed to have photophobia. Two weeks later he was readmitted and on this occasion his cerebrospinal fluid contained 1,350 cells per c.mm., of which $75 \%$ were polymorphonuclear. The protein content was $60 \mathrm{mg}$. \%, sugar $27 \mathrm{mg} . \%$, and again the culture was sterile. No cause for the relapse of his meningitis was found and he was treated with a course of chloromycetin, and later given a course of tetracycline. Serial lumbar punctures showed a progressive improvement in his cerebrospinal fluid, and coincidently his general condition improved.

Following discharge he remained well for a further seven months, when he was readmitted with a history of vomiting and crying for five days; on examination he had an upper respiratory tract infection, and the cerebrospinal fluid was found to be normal. He was discharged home but within a few days started vomiting. He again had photophobia, his mother thought he had been having

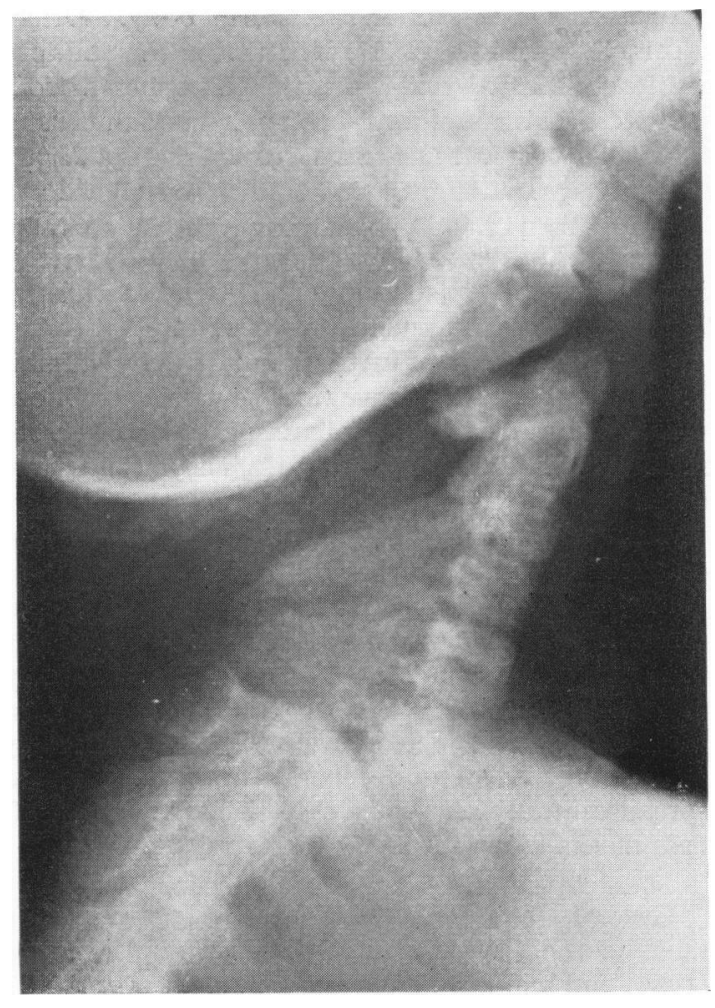

Fig. 1.-Lateral radiograph showing deformity of cervical spines. 
headaches, and the history suggested that he probably had a convulsion on the night before his readmission two weeks later. On examination he was found to have gross bilateral papilloedema. There was now a soft circumscribed swelling just below and to the left of the extended occipital protuberance. Examination of the skin overlying the swelling showed a small pore from which hairs protruded.

A plain radiograph of the skull showed a small bony defect in the occipital bone just to the left of the midline (Fig. 2).

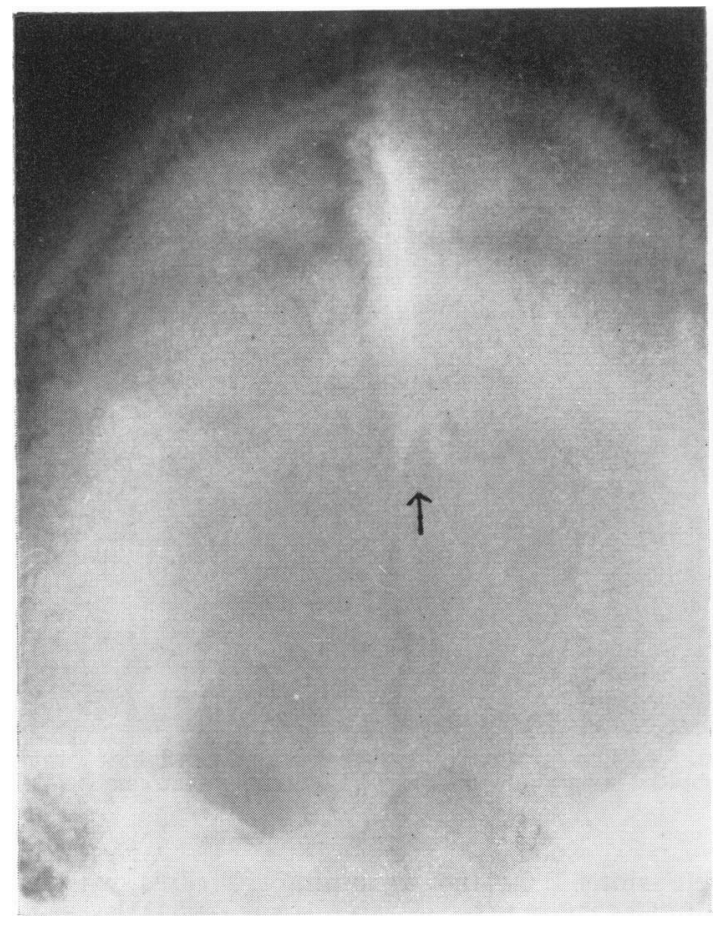

FIG. 2.-Radiograph of skull showing bony defect in occipital bone.

A ventriculogram showed symmetrically dilated but undisplaced lateral ventricles. The third ventricle was dilated and the aqueduct of Sylvius was kinked (Fig. 3). Some air passed through into the fourth ventricle which was not enlarged. The air passed freely down the spine but on returning to the skull most of it accumulated just below the foramen magnum. The findings were considered to be consistent with a mass in the posterior fossa.

The cerebrospinal fluid obtained by ventricular puncture contained 2 cells per c.mm. and less than $10 \mathrm{mg}$. \% of protein.

A pre-operative diagnosis of a dermoid cyst of the scalp associated with a congenital dermal sinus leading to an intracranial dermoid cyst was made, and a craniotomy performed on May 3. The scalp dermoid was excised and a sinus tract was found passing through the occipital bone into the posterior fossa just below the torcular. The dura was found to be very adherent at this point. On opening the posterior fossa a large cystic dermoid was found in the midline. Anteriorly the thin wall of the cyst had become adherent directly to the surrounding brain, and as it was not possible to remove the cyst intact the contents were first aspirated. The cyst was lined with a fairly thick wall of typical glistening desquamated epithelium, and in addition contained a hair. The collapsed cyst was then removed.

The fluid aspirated from the cyst contained numerous

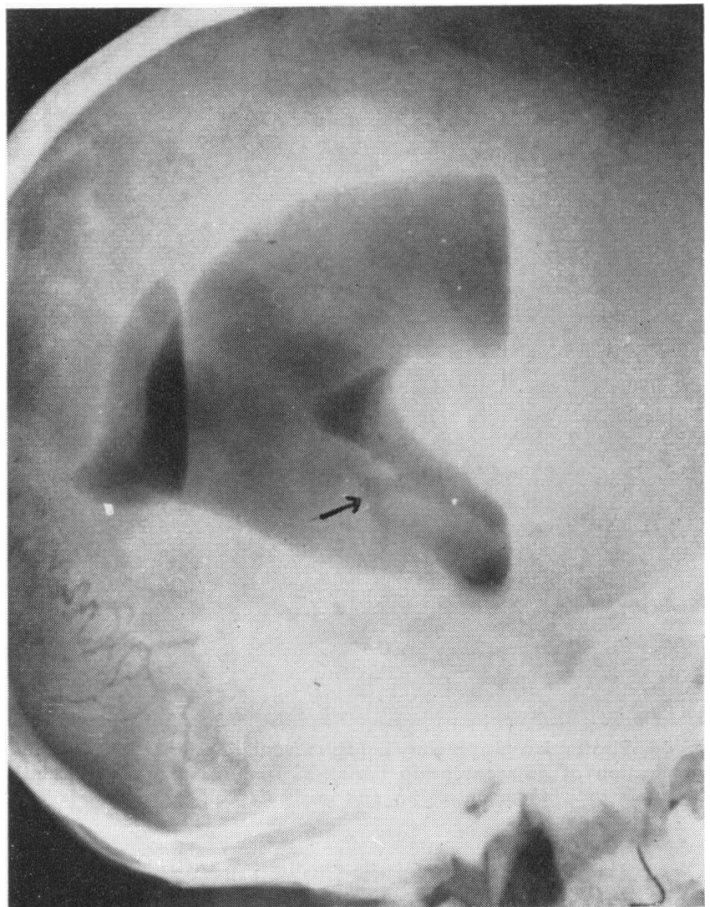

FIG. 3.-Ventriculogram demonstrating kinking of aqueduct of Sylvius by mass in posterior fossa.

pus cells and degenerate Gram positive cocci: it was sterile on culture.

Post-operatively he was given a course of tetracyline and his recovery was uneventful.

Pathological Report. The specimen consisted of a stalk of fibrous tissue, $3.75 \mathrm{~cm}$. in length, with a cystic mass at either end. The larger of these cysts was incomplete but appeared to have been approximately $4 \mathrm{~cm}$. in diameter. It had a thin but substantial membranous wall and contained pearly flakes of keratin. A solitary curly hair, $1.4 \mathrm{~cm}$. long, lay within the cyst near its attachment to the cord. The smaller tumour at the other end of the cord was irregular in shape and measured $1.75 \mathrm{~cm}$. in maximum diameter. It had a more fibrous wall, and contained yellowish-brown material and also one or two fine hairs. 
A transverse section through the interconnecting cord showed no visible lumen but a firm solid structure of fibrous appearance $2 \mathrm{~mm}$. in diameter.

Histology. The intracranial part of the specimen showed a cavity lined by keratinizing squamous epithelium. A few cerebeilar folia attached to it showed patchy degeneration of Purkinje cells but otherwise appeared normal. There was no dural tissue separating the two, but the pia-arachnoid was thickened and infiltrated with lymphocytes and polymorphonuclears (Fig. 4).

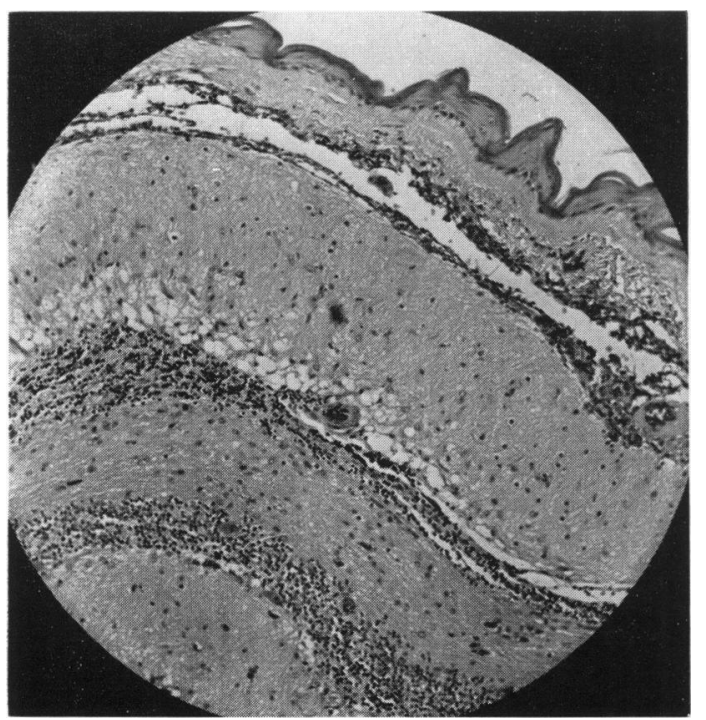

FIG. 4.-Photomicrograph showing intracranial cyst wall and patchy degeneration of adjacent brain tissue. No dural tissue is present. Haematoxylin and eosin $\times 50$.

A section through the stalk showed a solitary remnant of a piece of hair embedded in a core of fibrous tissue (Fig. 5).

The extracranial mass consisted of granulation tissue heavily infiltrated with acute and chronic inflammatory cells. It contained many fragments of hairs with conspicuous foreign-body giant cells, and also some keratinous debris. The diagnosis was of an intracranial dermoid cyst.

\section{Discussion}

During recent years there have been several papers reporting cases of congenital dermal sinus but the majority of these have been situated in the spinal axis (Cardell and Laurance, 1951; Perloff, 1954; Haworth and Zachary, 1955; Amador, Hankinson and Bigler, 1955).

Mount (1949) first described two cases of intracranial dermoid cyst associated with congenital dermal sinus. In both cases the cyst was infected forming an intracranial abscess.
Matson and Ingraham (1951) described 10 cases in which there were intracranial complications of congenital dermal sinuses. In nine of their cases the intracranial extension of the sinus was in the posterior fossa, and in the other case there was an infected dermoid cyst in the frontal fossa.

Logue and Till (1952) reviewed the literature and found 25 cases of posterior fossa dermoid cysts to which they added a further seven cases. Of these 32 cases, 22 had no dermal sinus or only an incom-

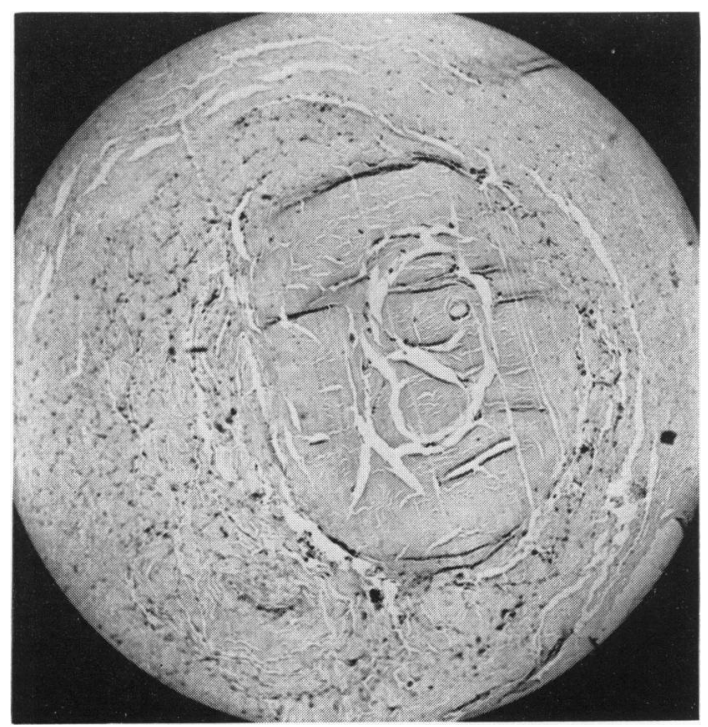

Fig. 5.-Photomicrograph of section through stalk showing a hair embedded in core of fibrous tissue. Haematoxylin and eosin $\times 42$.

plete sinus. Of the remaining 10 cases with a complete sinus there were seven in which the dermoid cyst was intradural and three were extradural.

More recently, Tytus and Pennybacker (1956) in their paper entitled 'Pearly Tumours in relation to the Central Nervous System' have described a further $\mathbf{4 3}$ cases of epidermoid and dermoid tumours. In their series there were eight cases in which the tumour was situated in the midline subtentorially, and of these, three were associated with dermoids of the scalp together with dermal sinuses. One of their patients also had multiple fusion defects of the vertebral column.

The site of the congenital dermal sinus opening is usually marked by a skin dimple, or the sinus may terminate in a cystic swelling in the scalp as in the case presented here. It is situated in the midline, either over the occiput or over the bridge of the nose. 
On close inspection hairs may be seen protruding from the mouth of the sinus.

Intracranial dermoid cysts occur most frequently in the posterior fossa, but may also occur at the base of the brain or within the ventricles.

In a child with a congenital dermal sinus a plain radiograph of the skull will invariably demonstrate a small bony defect.

Histologically the cyst wall is made up of squamous epithelium. The contents may be hair, teeth, bone, sebaceous material, masses of squamous epithelium and cholesterin crystals.

Complications frequently occur and fall into two groups: (1) The dermal sinus forms a natural tract, which allows infection to enter the central nervous system resulting in either an intracranial abscess or meningitis. (2) The intracranial cyst may enlarge and cause direct pressure effects on the brain, or it may cause signs and symptoms of raised intracranial pressure.

With regard to the treatment Matson and Ingraham (1951) state 'The treatment of choice is surgical excision of the entire dermal sinus tract from the skin surface to its deepest projection, including all cystic expansions, before infection has occurred or at least at a time when no infection is present'.

In the case presented here there was also the Klippel-Feil deformity. This is known to be associated with other congenital abnormalities of the central nervous system, among which Illingworth
(1956) has mentioned 'cholesteatoma' of the cerebellum. This tumour is now considered to be epidermoid in origin.

\section{Summary}

A case of recurrent meningitis due to an infected intracranial dermoid cyst is reported. The condition was associated with a congenital dermal sinus and the Klippel-Feil syndrome.

In any obscure case, and particularly any recurrent case of meningitis, it is recommended that a careful search should be made for any evidence of a congenital dermal sinus.

I wish to thank Dr. C. G. Parsons for permission to publish this case, and Mr. E. Turner for details of the operation and for his helpful advice. I should also like to thank Dr. K. B. Rogers for the bacteriological investigations, Dr. R. Astley for the radiographic findings, Dr. A. H. Cameron for the histological reports, Mr. J. G. Williamson for the photographs and Mr. D. R. Paton (Royal Hospital, Wolverhampton) for the photomicrographs.

\section{REFERENCES}

Amador, L. V., Hankinson, J. and Bigler, J. A. (1955). J. Pediat., $47,300$.

Cardell, B. S. and Laurance, B. (1951). Brit. med.J., 2, 1558. Cushing, H. (1932). Intracranial Tumours. Springfield, Illinois. Haworth, J. C. and Zachary, R. B. (1955). Lancet, 2, 10.

Hllingworth, R. S. (1956). Arch. Dis. Childh., 31, 8.

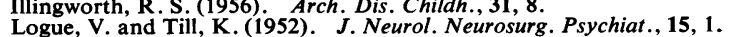
Matson, D. D. and Ingraham, F. D. (1951). Pediatrics, 8, 463. Mount, L. A. (1949). J. Amer. med. Ass., 139, 1263.

Perloff, M. M. (1954). J. Pediat., 44, 73.

Tytus, J. S. and Pennybacker, J. (1956). J. Neurol. Neurosurg. Psychiat., 19, 241. 